\title{
Pengaruh Gaya Kepemimpinan Transformasional dan Kepuasan Kerja terhadap Kinerja Guru Sekolah Dasar
}

\author{
*Alice Yeni Verawati Wote ${ }^{1}$, Jonherz Stenlly Patalatu ${ }^{2}$
}

${ }_{12}$ Pendidikan Guru Sekolah Dasar, Fakultas Keguruan dan Ilmu Pendidikan, Universitas Halmahera, Indonesia

\section{A R T I C L E I N F O \\ Article history: \\ Received 15 August 2019 \\ Received in revised form \\ 20 September 2019 \\ Accepted 10 October 2019 \\ Available online \\ 30November 2019}

Kata Kunci:

kepemimpinan, guru

kepuasan, kinerja.

Keywords:

school principle' leadership,

teachers, job satisfaction,

job performance

\begin{abstract}
A B S T R A K
Gaya kepemimpinan transformasional dan kepuasan kerja berpengaruh terhadap kinerja guru sekolah dasar, dengan kememinminan yang baik akan membaut suasana temoat kerja ebih baik. Penelitin ini bertujuan untuk mengukur pengaruh kepemimpinan transformasional kepala sekolah dan kepuasan kerja guru terhadap kinerja guru sekolah dasar di kecamatan Tobelo Tengah. Penelitian ini menggunakan metode survey dengan jumlah sampel penelitian sebanyak 52 orang guru. Hasil penelitian menunjukkan bahwa 1) Gaya kepemimpinan transformasional kepala sekolah berpengaruh positif terhadap kinerja guru dengan nilai thitung $=3.945>$ ttabel $=2.010$ pada taraf signifikan 0.05 . 2) kepuasan kerja guru berpengaruh positif terhadap kinerja guru dengan nilai thitung >ttabel yaitu $3.049>2.010$ pada taraf signifikan 0.05. Dan 3) gaya kepemimpinan kepala sekolah dan kepuasan kerja bersama-sama berpengaruh positif terhadap kinerja guru SD di Kecamatan Tobelo
\end{abstract} Tengah, dengan kontribusi sebesar 0.437 atau $43.7 \%$. Jadi dapat dikatakan bahwa gaya kemimpinan transformasional terhadap kinerja guru sekolah dasar, dimana gaya ini akan membuat suansana lebih nyaman.

\section{A B S T R A C T}

The aimed of this research is to determine the effect of principals' transformational leadership and job satisfaction toward teachers' job performance in elementary school in Tobelo Tengah' District. This research is using the survey method with the total number of the sample are 52 teachers. The result of this study shows: 1) Principals' transformational leadership has a positive effect on teachers' job performance which is tcount is $3.945>$ ttable 2.010 at the level of significant 0.05. 2) Teachers' job satisfaction has a positive effect to teachers' job performance which is tcount is $3.049>$ ttable 2.010 at the level of significant 0.05 , and 3) Principals' transformational leadership and teachers' job satisfaction simultaneous have a positive effect to teachers' job performance with total percentage is $43.7 \%$ or 0.437 .

\section{Pendahuluan}

Tujuan pendidikan nasional adalah untuk mengembangkan manusia Indonesia menjadi insan yang cerdas. Untuk menggapai tujuan itulah maka pemerintah mendirikan lembaga pendidikan yang dikenal sebagai sekolah. Sebagaimana halnya sebuah lembaga, sekolah juga dinahkodai oleh seorang pimpinan atau kepala sekolah. Merujuk pada Permendiknas nomor 28 tahun 2010 pasal 1 ayat 1 Kepala Sekolah adalah guru yang diberi tugas tambahan untuk memimpin taman kanak-kanak, taman kanak-kanak luar biasa, sekolah dasar atau madrasah ibtidaiyah, sekolah luar biasa, sekolah menengah pertama atau Madrasah Tsanawiyah, sekolah menengah atas atau Madrasah Aliyah, sekolah menengah kejuruan atau Madrasah Aliyah kejuruan atau sekolah menengah atas luar biasa, yang bukan sekolah bertaraf internasional, atau yang tidak dikembangkan menjadi sekolah bertaraf internasional. Dengan adanya tugas tambahan tersebut maka guru yang menjabat sebagai kepala sekolah memiliki tanggung jawab ganda yakni sebagai guru kelas atau tenaga pengajar maupun sebagai pemimpin yang tentu saja melekat tanggung jawab kepemimpinan.

Copyright (c) Universitas Pendidikan Ganesha. All rights reserved. 
Kepemimpinan atau leadership sendiri dapat diartikan sebagai sebuah proses sosial yang melaluinya seseorang dengan sengaja memberikan pengaruh kepada orang lain untuk menata perilaku dan hubungan mereka (Levy, 2010). Sedangkan (Keating, 1986) mengemukakan bahwa kepemimpinan merupakan suatu proses dengan berbagai cara mempengaruhi orang atau sekelompok orang untuk mencapai tujuan bersama. Berdasarkan kedua pengertian tersebut dapat disimpulkan bahwa kepemimpinan merupakan sebuah proses mempengaruhi orang lain yang ada dalam satu kelompok atau hubungan dalam rangka menata perilaku demi tercapainya tujuan bersama.

Apabila kepemimpinan dilihat dalam ranah pendidikan maka Rosmiati dan Kurniady (2011) menyatakan bahwa kepemimpinan pendidikan merupakan kemampuan untuk menggerakkan pelaksanaan pendidikan, sehingga tujuan pendidikan yang telah ditetapkan dapat tercapai secara efektif dan efisien. Berdasarkan pengertian ini maka dapat dikatakan bahwa Kepala Sekolah sebagai tenaga penggerak harus mampu menstimulir, mendorong, dan atau membimbing guru-guru menuju perkembangan yang berkesinambungan sehingga mereka mampu menjalankan tugas atau kinerjanya dengan optimal. Hal ini tentu saja berkaitan dengan gaya kepemimpinan seperti apa yang digunakan kepala sekolah dalam menjalankan tanggung jawabnya sebagai pemimpin.

Penelitian oleh (Suwarni, 2011) tentang pengaruh gaya kepemimpinan kepala sekolah terhadap Kinerja Guru Ekonomi menemukan bahwa gaya kepemimpinan kepala sekolah memberikan kontribusi yang signifikan terhadap kinerja guru ekonomi dalam mengajar, sehingga akhirnya kinerja guru ekonomi menjadi baik kemudian prestasi belajar siswa juga meningkat.

Ada beragam gaya kepemimpinan yang digunakan, namun sebagian besar model kepemimpinan mengadopsi gaya transformasional dan transaksional. Menurut Burn dan Bass (Saleem, 2015) kedua gaya kepemimpinan ini yang telah banyak digunakan diberbagai belahan dunia dan diteliti melalui studi kepemimpinan. Akan tetapi Bass dan Avolio (Garcia-Morales, V. J., Llorens-Montes, F. J., \& Verdu-Jover, 2008)) menyatakan bahwa gaya kepemimpinan transformasional biasanya menghasilkan kinerja yang lebih tinggi daripada kepemimpinan transaksional. Kepemimpinan transformasional lebih berfokus pada perubahan dan mengilhami pengikut untuk berkomitmen pada visi dan tujuan bersama suatu organisasi atau unit kerja, kepemimpinan transformasional juga menantang pengikutnya untuk menjadi pemecah masalah yang inovatif, serta mengembangkan kapasitas kepemimpinan pengikut melalui pembinaan, pendampingan, dan penyediaan tantangan dan dukungan ((Bass, B. M., \& Riggio, 2006).

Disamping mampu mengoptimalkan kinerja guru, (Siregar, 2019) berpendapat bahwa Kepala sekolah sebagai pemimpin pendidikan, harus mampu mengelola sarana dan prasarana pendidikan, pelayanan khusus sekolah dan fasilitas-fasilitas pendidikan lainnya sedemikian rupa sehingga guru-guru dan murid-murid memperoleh kepuasan dalam melaksanakan tugasnya. Kepuasan kerja dapat didefinisikan sebagai respons yang efektif atau emosional terhadap berbagai fakta menyangkut pekerjaan. Kepuasan kerja berkaitan dengan perasaan atau keadaan pikiran seseorang tentang sifat pekerjaan mereka. Lebih lanjut lagi (Arifin, 2014) menyatakan bahwa jika guru memiliki tingkat kepuasan kerja yang tinggi maka dapat dipastikan bahwa lingkungan sekolah akan lebih menyenangkan, lebih energik dan efektif yang secara tidak langsung akan memberikan pengaruh positif terhadap pencapaian akademik siswa. Berdasarkan asumsi di atas dapat disimpulkan bahwa kepuasan kerja merupakan salah satu faktor penentu bagi kinerja guru. Artinya semakin puas seorang guru terhadap pekerjaanya, maka semakin baik kinerjanya.

Tujuan dari penelitian ini adalah untuk mengetahui pengaruh kepemimpinan transformasional kepala sekolah dan kepuasan kerja terhadap kinerja guru sekolah dasar di kecamatan Tobelo Tengah.

\section{Metode}

Penelitian ini merupakan penelitian kuantitatif dengan menggunakan metode survey. Sampel pada penelitian ini berjumlah 52 orang guru yang tersebar di delapan sekolah dasar yang ada di Kecamatan Tobelo Tengah. Variabel penelitian ini adalah gaya kepemimpinan transformasioan (X1), kepuasan kerja guru (X2) sebagai variabel bebas dan kinerja guru variabel terikat (Y). Selanjutnya, untuk mengumpulkan data, peneliti menggunakan angket atau kuesioner. Masing-masing adalah angket kepemimpinan transformasional, angket kepuasan kerja guru dan angket kinerja guru.

\section{Hasil dan Pembahasan}

Data hasil penelitian terhadap variabel kinerja guru Sekolah Dasar (Y), Gaya Kepemimpinan Kepala Sekolah (X1), Kepuasan Kerja Guru (X2), yang telah dianalisis melalui statistik deskriptif yang disajikan dalam Tabel 1 sebagai berikut. 
Tabel 1. Rangkuman Hasil analisis Statistik Deskriptif

\begin{tabular}{lrrrr}
\hline \multicolumn{1}{c}{ Analisis } & \multicolumn{3}{c}{ Data variabel } & X2 \\
\hline Banyaknya data (n) & Y & & X1 & 52 \\
Minimum & 52 & 52 & 45 \\
Maximum & 87 & 45 & 126 \\
Range & 146 & 118 & 81 \\
Interval & 57 & 73 & 12 \\
Banyak Kelas & 8 & 11 & 7 \\
Mean & 7 & 7 & 105.35 \\
Std.Deviation & 117.46 & 99.27 & 22.80 \\
Variance & 13.00 & 13.29 & 519.88 \\
Median & 169.04 & 176.51 & 116.00 \\
Mode & 155.50 & 98.50 & 120 \\
\hline
\end{tabular}

Keterangan:

$\begin{array}{lll}\mathrm{Y} & : & \text { Kinerja Guru SD Kecamatan Tobelo Tengah } \\ \mathrm{X} 1 & : & \text { Gaya Kepemimpinan Kepala Sekolah } \\ \mathrm{X} 2 & : & \text { Kepuasan Kerja Guru }\end{array}$

Selanjutnya peneliti melakukan uji prasyarat yakni uji normalitas dan uji linieritas data. Hasil uji tersebut adalah sebagai berikut:

\section{Uji Normalitas}

Hipotesis yang diajukan dalam uji normalitas data adalah:

$\mathrm{H}_{0}$ : Data yang tidak berdistribusi normal

$\mathrm{H}_{1}$ : Data yang berdistibusi normal

Kriteria pengujian : tolak $\mathrm{H}_{0}$ jika nilai Asymp sig $<\alpha=0,05$. Hasil pengujian uji normalitas data penelitian dengan menggunakan One-Sample Kolmogorov-Smirnov Test termuat pada Tabel 2. dibawah ini.

Tabel 2. Rangukman Hasil Pengujian Normalitas

\begin{tabular}{lcc}
\hline \multicolumn{1}{c}{ One-Sample Kolmogorv-Smirnov Test } & Asymp.Sig & Alpha \\
\hline Kinerja Guru SD di Kec. Tobelo Tengah & 0.65 & 0.05 \\
Gaya Kepemimpinan Kepala SD SD di Kecamatan Tobelo Tengah & 0.89 & 0.05 \\
Kepuasan Kerja Guru SD di Kecamatan Tobelo Tengah & 0.03 & 0.05 \\
\hline
\end{tabular}

Berdasarkan tabel di atas maka dapat disimpulkan bahwa data kinerja guru, gaya kepemimpinan kepala sekolah dan kepuasan kerja guru berdistribusi normal atau menerima $\mathrm{H}_{1}$ (nilai Asymp sig $>\alpha$ ).

\section{Uji Linieritas}

Hasil pengujian signifikansi dan linieritas untuk masing-masing pengaruh gaya kepemimpinan kepala sekolah dan kepausan kerja guru terhadap kinerja guru dapat diuraikan sebagai berikut:

a. Signifikansi dan Linieritas Kinerja Guru (Y) atas Gaya Kepemimpinana Kepala Sekolah (X X $^{\text {SD di }}$ Kecamatan Tobelo Tengah.

Pengujian signifikansi dan linieritas ini untuk melihat apakah persamaan regresi yang dihasilkan baik atau tidak bias, sehingga bisa digunakan untuk memprediksi variabel dependen secara lebih tepat. Pengujiannya dilakukan menggunakan analisis varians yang menghasilkan nilai $\mathrm{F}$ sebagai parameternya. Untuk pengujian signifikansi, persamaan regresi $\mathrm{Y}$ atas $\mathrm{X}_{1}$ dikatakan signifikan jika nilai $F_{\text {hitung }}>F_{\text {tabel, }}$ sementara untuk uji linieritas dikatakan linier jika $F_{\text {hitung }}<F_{\text {tabel. }}$ Rangkuman perhitungan signifikansi dan linieritas regresi gaya kepemimpinan kepala sekolah atas kinerja guru dapat dilihat pada Tabel 3 di bawah ini: 
Tabel 3. Analisis Varians (ANAVA) Uji Signifikansi dan Linieritas Gaya Kepemimpinan Kepala Sekolah atas Kinerja Guru

\begin{tabular}{|c|c|c|c|c|c|c|}
\hline \multirow[t]{2}{*}{ Sumer Variansi } & \multirow[t]{2}{*}{ dk } & \multirow[t]{2}{*}{ JK } & \multirow[t]{2}{*}{ RJK } & \multirow[t]{2}{*}{ Fhitung } & \multicolumn{2}{|c|}{ Ftabel } \\
\hline & & & & & $\alpha=0,05$ & $\alpha=0,01$ \\
\hline Total & 52 & 37307664 & & & & \\
\hline Regresi (a) & 1 & 37299043.077 & & & & \\
\hline Regresi (b/a) & 1 & 2842.497 & 2842.497 & 24.596 & 4.03 & 7.17 \\
\hline Sisa (S) & 50 & 5778.426 & 115.569 & & & \\
\hline $\begin{array}{l}\text { Tuna Cocok } \\
\text { (TC) }\end{array}$ & 31 & 4069.676 & 131.280 & 1.46 & 2.07 & 2.84 \\
\hline Galat & 19 & 1708.750 & 89.934 & & & \\
\hline
\end{tabular}

Dari tabel ANAVA di atas terlihat untuk pengujian signifikansi $\mathrm{Y}$ atas $\mathrm{X}_{1}$ diperoleh $\mathrm{F}_{\text {hitung }}$ sebesar 24.596, sedangkan nilai sebesar $F_{\text {tabel }} 4.03$ pada tingkat kesalahan $\alpha=0,05$. Jika dibandingkan antara nilai $\mathrm{F}_{\text {hitung }}$ ternyata lebih besar dari nilai $\mathrm{F}_{\text {tabel }}(24.596>4.03)$, sehingga dapat disimpulkan bahwa persamaan regresi $\mathrm{Y}$ atas $\mathrm{X}_{1}$ adalah sangat signifikan. Sementara uji linieritas didapatkan $\mathrm{F}_{\text {hitung }}$ sebesar 1.46, sedangkan nilai sebesar $\mathrm{F}_{\text {tabel }} 2.07$ pada tingkat kesalahan $\alpha=0.05$ dengan $\mathrm{dk}$ pembilang 31 dan dk penyebut 19 . Nilai Fhitung $<$ Ftabel, sehingga dapat disimpulkan bahwa variabel gaya kepemimpinan kepala sekolah atas kinerja guru berbentuk linier.

b. Signifikansi dan Linieritas Kinerja $(\mathrm{Y})$ atas Kepuasan Kerja $\left(\mathrm{X}_{2}\right)$ Guru SD di Kecamatan Tobelo Tengah Pengujian signifikansi dan linieritas ini untuk melihat apakah persamaan regresi yang dihasilkan baik atau tidak bias, sehingga bisa digunakan untuk memprediksi variabel dependen secara lebih tepat. Pengujiannya dilakukan menggunakan analisis varians yang menghasilkan nilai $F$ sebagai parameternya. Untuk pengujian signifikansi, persamaan regresi $\mathrm{Y}$ atas $\mathrm{X}_{2}$ dikatakan signifikan jika nilai $F_{\text {hitung }}>$ Ftabel, sementara untuk uji linieritas dikatakan linier jika $F_{\text {hitung }}<F_{\text {tabel. }}$ Rangkuman perhitungan signifikansi dan linieritas regresi integritas atas kinerja guru dapat dilihat pada Tabel di bawah ini:

Tabel 4. Analisis Varians (ANAVA) Uji Signifikansi dan Linieritas Kepuasan Kerja atas Kinerja Guru

\begin{tabular}{|c|c|c|c|c|c|c|}
\hline \multirow{2}{*}{$\begin{array}{c}\text { Sumer } \\
\text { Variansi }\end{array}$} & \multirow[t]{2}{*}{ dk } & \multirow[t]{2}{*}{ JK } & \multirow[t]{2}{*}{ RJK } & \multirow[t]{2}{*}{ Fhitung } & \multicolumn{2}{|c|}{ Ftabel } \\
\hline & & & & & $\begin{array}{c}\alpha= \\
0,05\end{array}$ & $\alpha=0,01$ \\
\hline Total & 52 & 37307664 & & & & \\
\hline Regresi (a) & 1 & 37299043.077 & & & & \\
\hline Regresi (b/a) & 1 & 2220.942 & 2220.94 & 17.351 & 4.03 & 7.17 \\
\hline Sisa (S) & 50 & 6399.981 & 128.00 & & & \\
\hline $\begin{array}{l}\text { Tuna Cocok } \\
\text { (TC) }\end{array}$ & 27 & 3789.172 & 164.75 & 1.704 & 1.72 & 2.14 \\
\hline Galat & 51 & 2610.808 & 96.70 & & & \\
\hline
\end{tabular}

Keterangan: ${ }^{*}=$ Signifikansi pada $\alpha=0,05\left(F_{\text {hit }}>F_{\text {tab }}\right)$ dan ${ }^{* *}=$ linieritas pada $\alpha=0,05\left(F_{h i t}<F_{\text {tab }}\right)$.

Dari tabel ANAVA di atas terlihat untuk pengujian signifikansi $\mathrm{Y}$ atas X2 diperoleh Fhitung sebesar 17.351, sedangkan nilai sebesar $\mathrm{F}_{\text {tabel }} 4.03$ pada tingkat kesalahan $\alpha=0,05$. Jika dibandingkan antara nilai $\mathrm{F}_{\text {hitung }}$ ternyata lebih besar dari nilai $\mathrm{F}_{\text {tabel }}(17.351>4.03)$, sehingga dapat disimpulkan bahwa persamaan regresi $\mathrm{Y}$ atas X2 adalah sangat signifikan. Sementara uji linieritas didapatkan Fhitung sebesar 1.704, sedangkan nilai sebesar Ftabel 1,72 pada tingkat kesalahan $\alpha=0.05$ dengan dk pembilang 27 dan dk penyebut 51 . Nilai $\mathrm{F}_{\text {hitung }}<\mathrm{F}_{\text {tabel, }}$, sehingga dapat disimpulkan bahwa variabel kepuasan kerja atas kinerja guru berbentuk linier.

\section{Uji Hipotesis Penelitian}


Setelah berbagai analisis dilakukan, maka selanjutkan di lakukan pengujian hipotesis untuk mengukur besarnya pengaruh positif antara variabel penelitian. Deskripsi hasil perhitungan yang telah dilakukan dengan menggunakan anlisis regresi terhadap hipotesis penelitian yang dijabarkan sebagai berikut:

Tabel 5. Koefisien Regresi Berganda Pengaruh Gaya Kepemimpinan Kepala Sekolah dan Kepuasan Kerja Terhadap Kinerja Guru SD di Kecamatan Tobelo Tengah.

\begin{tabular}{|c|c|c|c|c|c|c|}
\hline & \multirow[t]{2}{*}{ Model } & \multicolumn{5}{|c|}{ Standardized } \\
\hline & & B & Std. Error & $\begin{array}{c}\text { Coefficients } \\
\text { Beta }\end{array}$ & $\mathrm{T}$ & Sig. \\
\hline \multirow[t]{3}{*}{1} & (Constant) & 52.605 & 10.921 & & 4.817 & .000 \\
\hline & $\begin{array}{l}\text { Gaya Kepemimpinan } \\
\text { Kepala Sekolah }\end{array}$ & .442 & .112 & .452 & 3.945 & .000 \\
\hline & Kepuasan Kerja Guru & .199 & .065 & .349 & 3.049 & .004 \\
\hline $\mathrm{a}$ & Dependent Variable: Kin & rja Guru & & & & \\
\hline
\end{tabular}

1. Gaya Kepemimpinan Kepala Sekolah Berpengaruh Positif Terhadap Kinerja Guru SD di Kecamatan Tobelo Tengah

Hipotesis statistik dapat dirumuskan sebagai berikut:

$\mathrm{H}_{0}: \beta 1 \leq 0$

$\mathrm{H}_{1}: \beta 1>0$

Kriteria pengujian: tolak $\mathrm{H}_{0}$ jika $t_{\text {hitung }} \geq \mathrm{t}_{\text {tabel }}$ dan terima $\mathrm{H}_{0}$ jika $\mathrm{t}_{\text {hitung }}<\mathrm{t}_{\text {tabel. }}$. Berdasarkan hasil perhitungan diperoleh $\mathrm{b} 1=0.452$ dengan $t_{\text {hitung }}=3.945$ dan $t_{\text {tabel }}$ untuk $\alpha=0.05$ dan dk $=50$ adalah 2.010. Dari perhitungan diperoleh nilai thitung $=3.945>t_{\text {tabel }}=2.010$. Maka tolak $\mathrm{H}_{0}$ atau $\mathrm{H}_{1}$ diterima, yang berarti bahwa terdapat pengaruh positif gaya kepemimpinan kepala sekolah terhadap kinerja guru SD di Kecamatan Tobelo Tengah.

\section{Kepuasan Kerja Berpengaruh Positif Terhadap Kinerja Guru SD di Kecamatan Tobelo Tengah}

Hipotesis statistik dapat dirumuskan sebagai berikut:

$\mathrm{H}_{0}: \beta 2 \leq 0$

$\mathrm{H}_{1}: \beta 2>0$

Kriteria pengujian: tolak $\mathrm{H}_{0}$ jika $t_{\text {hitung }} \geq t_{\text {tabel }}$ dan terima $\mathrm{H}_{0}$ jika $t_{\text {hitung }}<\mathrm{t}_{\text {tabel. }}$ Berdasarkan hasil perhitungan diperoleh $\mathrm{b} 2=0,349$, dengan thitung $=3.049$ dan tabel untuk $\alpha=0.05$ dan dk $=50$ adalah 2.010. Dari perhitungan diperoleh nilai $t_{\text {hitung }}>t_{\text {tabel }}$ yaitu $3.049>2.010$. Maka tolak $\mathrm{H}_{0}$ atau $\mathrm{H}_{1}$ diterima, yang berarti terdapat pengaruh positif kepuasan kerja terhadap kinerja guru SD di Kecamatan Tobelo Tengah.

3. Gaya Kepemimpinan dan Kepuasan Kerja Secara Bersama-sama Berpengaruh Positif Terhadap Kinerja Guru SD di Kecamatan Tobelo Tengah

Hipotesis statistik dapat dirumuskan sebagai berikut:

$\mathrm{H}_{0}: \rho \mathrm{y} 12 \leq 0$

$\mathrm{H}_{1}: \rho \mathrm{y} 12>0$

Kriteria pengujian: tolak $\mathrm{H}_{0}$ jika thitung $\geq \mathrm{t}_{\text {tabel }}$ dan terima $\mathrm{H}_{0}$ jika thitung $<\mathrm{F}_{\text {tabel. }}$ Maka untuk menguji hipotesis akan diuraikan pada tabel 6 berikut:

Tabel 6. Hasil Uji Regresi F-hitung Variabel Penelitian

\begin{tabular}{|c|c|c|c|c|c|c|}
\hline Model & & Sum of Squares & Df & Mean Square & $\mathrm{F}$ & Sig. \\
\hline \multirow[t]{3}{*}{1} & Regression & 3763.878 & 2 & 1881.939 & 18.986 & $.000^{\mathrm{a}}$ \\
\hline & Residual & 4857.045 & 49 & 99.123 & & \\
\hline & Total & 8620.923 & 51 & & & \\
\hline \multicolumn{7}{|c|}{ a. Predictors: (Constant), X2, X1 } \\
\hline \multicolumn{7}{|c|}{ b. Dependent Variable: Y } \\
\hline
\end{tabular}


Dari perhitungan diperoleh $\mathrm{F}_{\text {hitung }}=18.986$, dengan $\mathrm{F}_{\text {tabel }}=3.18$ pada $\alpha=0.05$ dan dk pembilang $=$ 2 dan $\mathrm{dk}$ penyebut $=49$, dengan persamaan regresi $\hat{y}=0,452 \times 1+0,349 \times 2$. Maka tolak $\mathrm{H}_{0}$ atau $\mathrm{H}_{1}$ diterima, artinya gaya kepemimpinan kepala sekolah dan kepuasan kerja bersama-sama berpengaruh positif terhadap kinerja guru SD di Kecamatan Tobelo Tengah, dengan memberikan kontribusi sebesar 0.437 (43.7\%) sedangkan sisanya 0.563 (56.3\%) dipengaruhi oleh faktor lain.

Berdasarkan hasil analisis ditemukan bahwa kepemimpinan transformasional berpengaruh positf terhadap kinerja guru Sekolah Dasar di Kecamatan Tobelo Tengah. Artinya semakin tinggi kepemimpinan transformasional kepala sekolah maka semakin meningkat kinerja guru. (Andreani \& Petrik, 2016) melalui penelitiannya menjelaskan alasan mengapa kepemimpinan transformasional memberikan pengaruh yang signifikan terhadap kinerja karyawan yaitu bahwa kepemimpinan transformasional dapat mempengaruhi karyawan untukberkontribusi secara ikhlas terhadap perusahaan. Mereka juga bersedia menyumbangkan ide-ide mereka agar perusahaan dapat memperoleh hasil yang terbaik. Selain itu, karyawan juga menyelesaikan pekerjaan dengan sempurna dan melakukan pekerjaan sesuai dengan jumlah yang dibutuhkan. Alasan ini selaras dengan peryataan olehYulk (Andreani \& Petrik, 2016) bahwadengan kepemimpinan transformasional, para pengikut merasakan kepercayaan, kekaguman, kesetiaan, dan rasa hormat terhadap pemimpin, dan mereka termotivasi untuk melakukan lebih dari yang semula diharapkan mereka lakukan.Lebih dari itu menurut Bass dan Riggio (2006) pemimpin transformasional memberdayakan pengikutnya dan memperhatikan kebutuhan individu dan pengembangan pribadi mereka, membantu pengikut untuk mengembangkan potensi kepemimpinan mereka sendiri.

Penelitian oleh (Kovjanic, S. Schuh, S. C.,\& Jonas, 2013) menemukan bahwa kepemimpinan transformasional secara tidak langsung berpengaruh terhadap kinerja karyawan. Pengaruh tidak langsung ini disebabkan oleh adanya variabel moderator yakni kepuasan kerja artinya kepemimpinan transformasional dan kinerja karyawan dimoderatori oleh kepuasan kerja. Semakin tinggi kepuasan kerja karyawan terhadap kepemimpinan maka kinerjanya akan semakin baik. Sementara pada penelitian ini, peneliti menjadikan kepuasan kerja sebagai variabel bebas dan hasil yang diperoleh adalah terdapat pengaruh positif kepuasan kerja terhadap kinerja guru. Hasil penelitian ini dikuatkan oleh penelitian sebelumnya yang dilakukan oleh (Werang, 2014) yang menemukan bahwa kepuasan kerja berpengaruh secara signifikan terhadap kinerja guru SDN di kota Marauke. Penelitian lain yang memiliki hasil serupa juga dilakukan oleh Putrana, Fathoni, dan Warso (2016) yang menemukan bahwa kepuasan kerja mempunyai pengaruh positif dan signifikan terhadap kinerja karyawan. Ketiga penelitian ini mengindikasikan bahwa semakin tinggi tingkat kepuasan kerja guru maka semakin meningkat juga kinerjanya.

Hasil yang ketiga dari penelitian ini menunjukkan bahwa kepemimpinan transformasional kepala sekolah dan kepuasan kerja bersama-sama berpengaruh positif terhadap kinerja guru SD di Kecamatan Tobelo Tengah, dengan memberikan kontribusi sebesar 0.437 (43.7\%) sedangkan sisanya 0.563 (56.3\%) dipengaruhi oleh faktor lain. Ini sejalan dengan penelitian (Werang, 2014)ynag menunjukkan kepuasan kerja guru berpengaruh secara signifikan terhadap moral kerja guru SD Negeri di Kota Merauke.Peneliti berasumsi bahwa faktor lain tersebut misalnya masa kerja dan usia responden. Asumsi ini diperkuat dengan penelitian oleh (Aprilyanti, 2017) yang meneliti tentang pengaruh masa kerja dan usia terhadap produktivitas kerja karyawan PT. Oasis Water International, hasil penelitiannya menjunjukan bahwa masa kerja dan usia memiliki pengaruh sebesar 8,3\% terhadap produktivitas kerja. Selain itu ada juga faktor kompetensi guru sebagaimana diteliti oleh Pudjiastuti dan Sriwidodo (2011) yang menunjukkan ada pengaruh positif kompetensi guru terhadap kinerja guru.

\section{Simpulan dan Saran}

Berdasarkan hasil analisis data dan pembahasan maka dapat disimpulkan bahwa:1) Kepemimpinan transformasional kepala sekolah memberikan pengaruh positif terhadap kinerja guru Sekolah Dasar di kecamatan Tobelo Tengah, 2) Kepuasan kerja guru berpengaruh positif terhadap kinerja guru Sekolah Dasar di Kecamatan Tobelo Tengah, 3) Kepemimpinan transformasional kepala sekolah dan kepuasan kerja guru secara bersama-masa berpengaruh positif terhadap kinerja guru Sekolah Dasar di kecamatan Tobelo Tengah

Dari hasil penelitian ini maka disarankan kepada Kepala Sekolah Dasar di Kecamatan Tobelo Tengah agar dalam pelaksanaan tugasnya sebagai pemimpin, tetap menggunakan gaya kepemimpinan transformasional, sebab gaya kepemimpinan tersebut memberikan pengaruh terhadap kinerja guru. Selain itu, kepala sekolah juga perlu memperhatikan kepuasan kerja guru sebab kepuasan kerja guru juga berdampak terhadap kinerjanya sehingga hal-hal menyangkut gaji, tunjangan, serta ketersediaan ruang kerja yang nyaman harus diperhatikan. 
Bagi penelitian selanjutnya, peneliti menyarankan agar memperhatikan faktor-faktor lain yang dapat menjadi variabel penentu peningkatan kinerja guru yang dapat dijadikan rujukan bagi penelitian selanjutnya.

\section{Daftar Rujukan}

Andreani, F., \& Petrik, A. (2016). Employee Performance as The Impact of Transformational Leadership and Job Satisfaction in PT Anugerah Baru Denpasar. Jurnal Manajemen Dan Kewirausahaan, 18(1), 25-32. https://doi.org/10.13189/ujm.2016.040404

Aprilyanti, S. (2017). Pengaruh Usia dan Masa Kerja Terhadap Produktivitas Kerja (Studi Kasus: PT. OASIS Water International Cabang Palembang). Jurnal Sistem Dan Manajemen Industri, 1(2), 68. https://doi.org/10.30656/jsmi.v1i2.413

Arifin, Z. (2014). . Evaluasi Pembelajaran: Prinsip Teknik Prosedur. PT Remaja Rosdakarya.

Bass, B. M., \& Riggio, R. E. (2006). Transformational leadership (2nd ed.). Lawrence Erlbaum Associates.

Garcia-Morales, V. J., Llorens-Montes, F. J., \& Verdu-Jover, A. J. (2008). The effects of transformational leadership on organizational performancethrough Knowledge and Innovation.

Keating. (1986). Kepemimpinan. Teori dan Pengembangannya. (terjemahan; A.M. Mangunhardjana). Kanisius.

Kovjanic, S. Schuh, S. C.,\& Jonas, K. (2013). Transformational leadership and performance: An experimental investigation of the mediating effects of basic needs satisfaction and work engagement. Journal of Occupational and Organizational Psychology, 86(4), 543-555. https://doi.org/https://doi.org/10.1111/joop.12022

Levy, P. E. (2010). Industrial organizational psychology; understanding the workplace (3rded.). Worth Publisher.

Saleem, H. (2015). The Impact of Leadership Styles on Job Satisfaction and Mediating Role of Perceived Organizational Politics. Procedia - Social and Behavioral Sciences, 172, 563-569. https://doi.org/10.1016/j.sbspro.2015.01.403

Siregar, F. A. (2019). Peningkatan Kompetensi Kepala Sekolah Dalam Upaya Meningkatkan Mutu Pendidikan Oleh: IJTIMAIYAH, 2(1).

Suwarni. (2011). Pengaruh Gaya Kepemimpinan Kepala Sekolah dan Budaya Sekolah terhadap Kinerja Guru. JURNAL PENDIDIKAN DAN PEMBELAJARAN, 18(2).

Werang, B. R. (2014). Teachers ' Work Morale, and Teachers ' Work Satisfaction on Teachers ' Work Performance At State Primary Schools. Cakrawala Pendidikan, 128-137. 